\title{
Concurrent femoral neck fractures following pelvic irradiation: a
} case report Raphael Omotayo Ayorinde*1 and Clement Abu Okolo²

Address: ${ }^{1}$ Department of Orthopaedic and Trauma, University College Hospital, Ibadan, Nigeria and ${ }^{2}$ Department of Pathology, University of Ibadan/University College Hospital, Ibadan, Nigeria

Email: Raphael Omotayo Ayorinde* - raphaelayorinde@yahoo.com; Clement Abu Okolo - clemabuokolo@yahoo.ca

* Corresponding author

Published: 16 December 2009

Journal of Medical Case Reports 2009, 3:9332 doi:10.1 186/1752-1947-3-9332

Received: 4 November 2008

Accepted: 16 December 2009

This article is available from: http://www.jmedicalcasereports.com/content/3/I/9332

(C) 2009 Ayorinde and Okolo; licensee BioMed Central Ltd.

This is an Open Access article distributed under the terms of the Creative Commons Attribution License (http://creativecommons.org/licenses/by/2.0), which permits unrestricted use, distribution, and reproduction in any medium, provided the original work is properly cited.

\begin{abstract}
Introduction: Fracture of the neck of the femur is common in older people. It often occurs in a single hip, with osteoporosis being the most common cause. Sometimes this fracture may also occur following pelvic irradiation, though this is not common. To the best of our knowledge, we present the first reported case in Nigeria of concurrent bilateral fractures of the femoral neck following pelvic irradiation.
\end{abstract}

Case presentation: A 74-year-old Nigerian woman presented at our surgical outpatients department with a 5-month history of pain in both hips and a 4-month history of inability to walk. She had had pelvic irradiation for carcinoma of the cervix 2 years earlier. Pelvic radiographs confirmed bilateral subcapital neck fractures.

Conclusion: Patients with hip pain who have been treated with pelvic irradiation should be thoroughly investigated for hip fractures.

\section{Introduction}

Hip fractures are common in older people and are a major source of morbidity and mortality, especially in women. Most of these fractures are related to osteoporosis and are often precipitated by trivial injuries. However, it is well documented that therapeutic radiation can result in bone damage and may increase the risk of fracture [1]. Magnetic resonance imaging and standard radiographs of the hips are useful diagnostic tools [2]. We report a case of bilateral femoral neck fractures presenting after radiotherapy for a gynaecological malignancy.

\section{Case presentation}

A 74-year-old Nigerian woman was referred to our surgical outpatients department from the Radiotherapy Department in September 2007 with a 5-month history of pain in both hips and a 4-month history of inability to walk. The pain had started in the right hip and involved the left hip about a month later. The pain was insidious and was associated with a worsening limp, which required her to walk with the aid of a walking stick. She had been bedridden for about 4 months before presentation but she had no history of falls.

She had been diagnosed with a stage $1 \mathrm{~b}$ invasive squamous cell carcinoma of the cervix 2 years before presentation and was treated primarily with 45Gy of external radiation therapy for 42 days in fractionated doses and had been symptom-free thereafter. A pelvic radiograph showed subcapital fractures of both femurs, with osteonecrosis of the heads (Figure 1). 


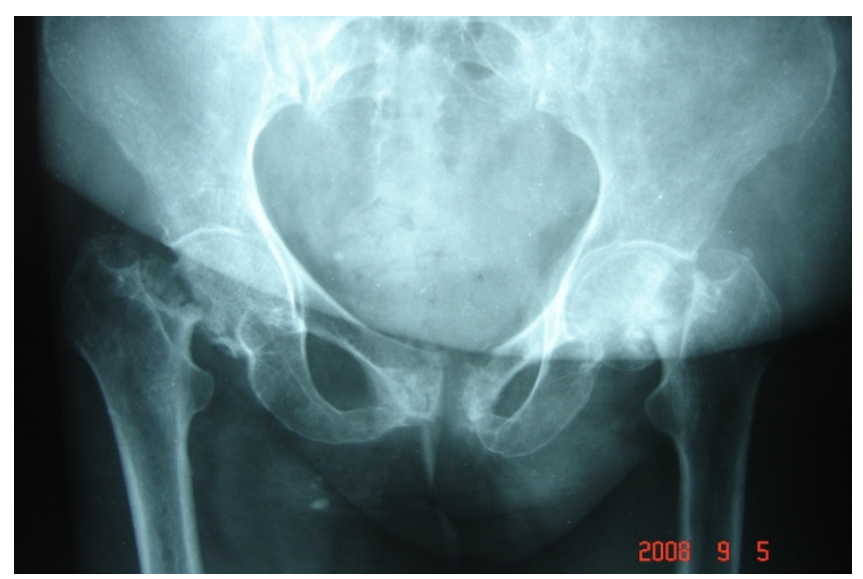

Figure I

Pre-operative antero-posterior radiograph.

She underwent bilateral hemiarthroplasty with noncemented Austin Moore stems at 8-week intervals (Figures 2 and 3). The histology showed osteoporosis and necrosis, but no malignant cells. The patient is now pain free and walks with a Zimmer frame.

\section{Discussion}

Radiotherapy is the mainstay of treatment of advanced female pelvic malignancies, either in curative or palliative settings [3]. The bony structures of the pelvis and groin lie in close proximity to the genitourinary pelvic organs, gastrointestinal pelvic organs, and the lymphatic drainage of these organs. Therefore, during irradiation, there is an associated high rate of morbidity related to pelvic organs. However, damage to the bones is rarely taken into account, because they are relatively radioresistant. The main evidence of the effect of irradiation on fracture risk comes from a long-term follow-up study of two European

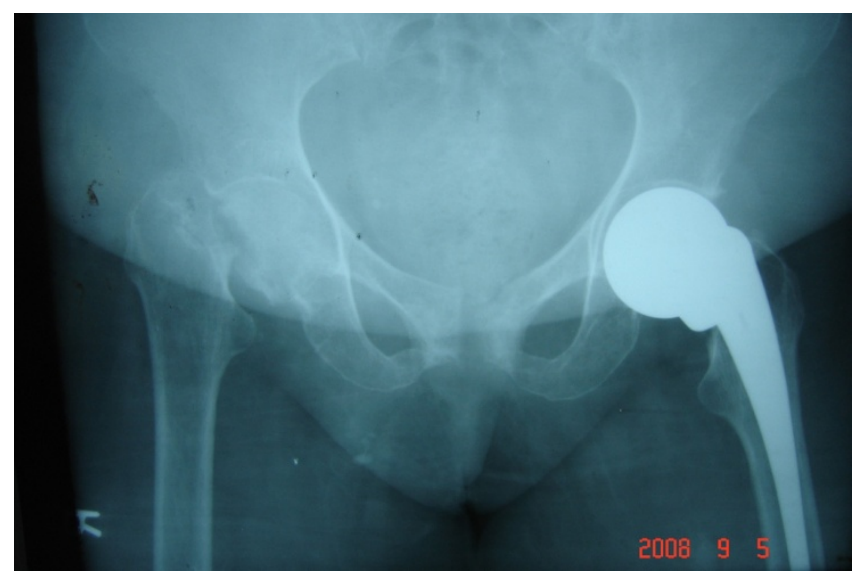

Figure 2

Pelvic radiograph after left hip hemiarthroplasty.

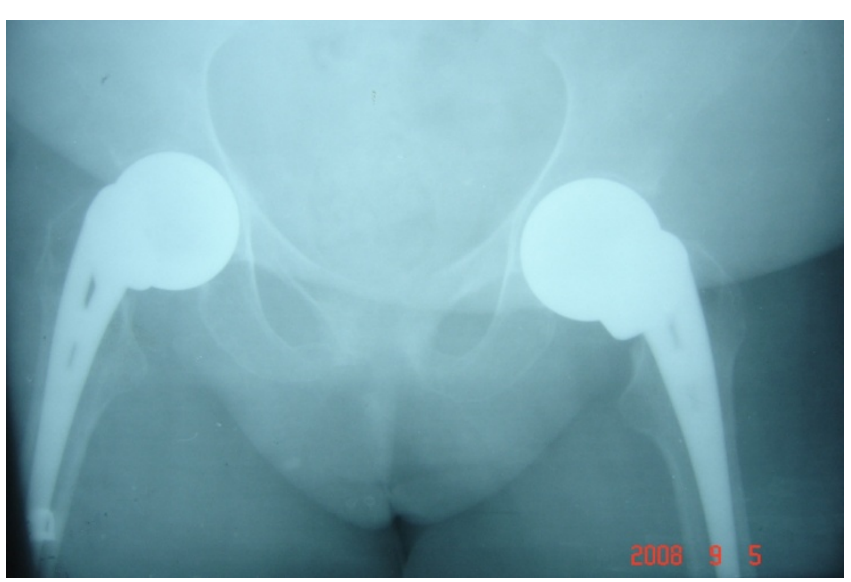

Figure 3

Pelvic radiograph after bilateral hip hemiarthroplasty.

randomised trials (Stockholm I and II) evaluating the effect of short-course irradiation in patients with operable rectal cancer $[4,5]$. It was established that the patients who underwent short-course irradiation were twice as likely to be admitted to hospital with hip fractures as patients who did not undergo irradiation.

Bilateral femoral neck fractures have also been reported in the literature as resulting from long-term steroid therapy, chronic renal insufficiency, in patients with abnormal anatomy of the neck of the femur and as stress fractures in young athletes [6-9]. Our patient, however, did not match any of these conditions.

A search through the medical records in our hospital and in our regional journals showed no patient presenting with hip fracture following pelvic irradiation. This may indicate that African blacks are less likely to develop pelvic fractures following irradiation, although Nancy et al. [1] did not find any statistical interaction between race and irradiation therapy. Another reason could be that many of our patients who had been treated may not have lived long enough to develop radiation-induced fractures of the hip. The late presentation and diagnosis of the hip fractures in this patient is worthy of note. The patient presented with hip pain, for which she was treated with analgesics only; no radiological investigation was done until the patient was bed ridden. The rarity of this condition in our hospital may have been responsible for the low index of suspicion. The presentation of this patient fits into the classical symptom and signs suggested by LaVelle, "prodromal pain localised to the hip or radiating to the knee, followed by a gradually increasing limp and disability, as might occur with a slipped femoral epiphysis. Although the patient is able to walk, coxa vara deformity may have already occurred" [10]. Hip pain in patients 
treated with pelvic irradiation should make the physician suspect radiation-induced insufficiency fractures of the pelvis. In the study by Feltl et al. [3], all patients with symptomatic pelvic bone fractures had pain as the first symptom. The roentgenographic characteristics are well described by Stephenson and Cohen [11] and suggest that diagnosis of these fractures could be made on plain X-ray before complete fractures occurred. Computed tomography and magnetic resonance imaging [12] are also useful in evaluating hip pain in patients treated with pelvic irradiation.

\section{Conclusion}

African blacks are predisposed to hip fractures following pelvic irradiation. Hip pain in patients who have had pelvic irradiation should therefore be thoroughly investigated for hip fractures. It should also be noted that complications following irradiation may present months or years later.

\section{Consent}

Written informed consent was obtained from the patient for publication of this case report and any accompanying images. A copy of the written consent is available for review by the Editor-in-Chief of this journal.

\section{Competing interests}

The authors declare that they have no competing interests.

\section{Authors' contributions}

ROA managed the patient, conceptualised the write up, and wrote the initial draft of the manuscript. CAO performed the histological examination of the excised heads, and was a major contributor to the manuscript, especially the histological results. Both authors read and approved the final manuscript.

\section{References}

I. Nancy NB, Elizabeth BH, Joel ET, Sara BD, Beth AV: Risk of pelvic fractures in older women following pelvic irradiation. JAMA 2005, 23/30:2587-2593.

2. Zuckerman JD, Shin SS, Polatsch DB, Schweitzer M: Concurrent bilateral femoral neck stress fractures and osteonecrosis of the hip. J Bone Joint Surg 2006, 88:857-860.

3. Feltl D, Vosmik M, Jirasek M, Stahalova V, Kubes J: Symptomatic osteoradionecrosis of the pelvic bones in patients with gynaecological malignancies - result of a long-term followup. Int J Gynecol Cancer 2006, I 6:478-483.

4. Cedermark B, Johansson H, Rutqvist LE, Wilking N: Stockholm I trial of preoperative short term radiotherapy in operable rectal carcinoma: a prospective randomized trial. Cancer 1995, 75:2269-2275.

5. Stockholm Colorectal Cancer Study Group: Randomized study on preoperative radiotherapy in rectal carcinoma. Ann Surg Oncol 1996, 3:423-430.

6. Haddad FS, Mohanna PN, Goddard NJ: Bilateral femoral neck stress fractures following steroid treatment. Injury 1997, 28:67I-673.

7. Tarr RW, Kaye JJ, Nance EP Jr: Insufficiency fractures of the femoral neck in association with chronic renal failure. South Med J | 988, 8 |:863-866.
8. Annan IH, Buxton RA: Bilateral stress fractures of the femoral neck associated with abnormal anatomy - a case report. Injury 1986, I 7:164-166.

9. Bailie DS, Lamprecht DE: Bilateral femoral neck stress fractures in an adolescent male runner - a case report. Am J Sports Med 200I, 29:8I I-8I3.

10. LaVelle DG: Fractures of hip. In Campbell's Operative Orthopaedics Volume 3. 10th edition. Edited by: Canale ST. Philadelphia: Mosby; 2003.

II. Stephenson WH, Cohen B: Post-irradiation fractures of the neck of the femur. J Bone Joint Surg 1956, 38B:830.

12. Blomlie V, Rofstad EK, Talle K, Sundfor K, Winderen M, Lien $\mathrm{HH}$ : Incidence of radiation-induced insufficiency fractures of the female pelvis: evaluation with MR imaging. AJR Am J Roentegol 1996, 167:1205-1210.

\section{Publish with Bio Med Central and every scientist can read your work free of charge}

"BioMed Central will be the most significant development for disseminating the results of biomedical research in our lifetime. "

Sir Paul Nurse, Cancer Research UK

Your research papers will be:

- available free of charge to the entire biomedical community

- peer reviewed and published immediately upon acceptance

- cited in PubMed and archived on PubMed Central

- yours - you keep the copyright

Submit your manuscript here:

http://www.biomedcentral.com/info/publishing_adv.asp
BioMedcentral 